\title{
The Assessment of Business Process Management Maturity: Comparative Analysis Inside an Organization
}

\author{
Renata Gabryelczyk \\ University of Warsaw, Poland
}

\section{Abstract}

The purpose of this paper is to create and test the practical application of the business process management maturity assessment based on a case study. Maturity models are used for measuring the performance and maturity of individual functional areas or processes, as well as that of the whole organization. We propose measuring the maturity of business process management on a sample of 47 employees of one organization at two different grade levels: at the Management level and at the Professionals level. The comparative analysis of business process management maturity was performed using an ANOVA test, which allowed the evaluation of differences between the groups of respondents and using correlation matrix, which assesses the strength of the correlation between the business process maturity in the organization and six process areas (Strategy, Documentation, Optimization, Implementation, Execution, Controlling), which are constituent the maturity. The analysis of differences in the perception of business process management maturity through different employees may help better prioritize BPM development projects in an organization. The findings will be the basis for formulating recommendations for the effective raising of the business process management maturity.

Keywords: business process management, maturity of business process management, maturity models

JEL classification: $M$

Acknowledgments: Digital Economy Lab University of Warsaw,

http://www.delab.uw.edu.pl/

\section{Introduction}

Maturity models are used for measuring the performance and maturity of individual functional areas or processes, as well as that of the whole organization (Crosby, 1979; Hammer, 2007; Rosemann and de Bruin, 2005; Rosemann et al., 2006; OMG, 2008; McCormack and Johnson, 2001; Lockamy and McCormack, 2004). Business Process Maturity is the ability of an organization to control its processes efficiently, i.e. to define, implement and measure its processes as well as to make continual improvement decisions based on performance measurements. The process of achieving maturity is associated with developing some features characteristic for the given maturity level (Hammer, 2007; Rosemann and de Bruin, 2005; Rosemann et al., 2006; OMG, 2008; McCormack and Johnson, 2001; Lockamy and McCormack, 2004; Zwicker et al., 2010) and improving the process management areas according to the Business Process Lifecycle (Jost and Scheer, 2002) or Process Management Life Cycle (BOC, 2007). 
The purpose of this paper is to create and test the practical application of the business process management maturity assessment based on a case study of a large company representing the fuel sector. The survey covered six process areas distinguished in the PMLC model (Strategy, Documentation, Optimization, Implementation, Execution, Controlling) and was conducted on a group of organization's employees representing two different grade levels: the Management and the Professionals. To begin with, research questions were formulated. RQ1: Is the employees' perception of the organization's process areas maturity the same for both grade levels? RQ2: Which of the process areas are most relevant to improving the organization's process maturity in the opinion of employees representing different grade levels? For the purpose of expressing the perception of the analysed areas maturity in quantitative terms, a Business Process Maturity Indicator was designed. It enabled the ANOVA Simple Factor analysis to be performed in order to answer RQ1 and the investigation of the correlation between the general maturity of the organization and the maturity components according to the PMLC stages - to answer RQ2.

\section{Maturity Models in Business Process Management}

When talking about processes, the notion of "maturity" is most typically defined as the capability of the organization and its processes to systematically deliver improved outcomes of its activity (Rosemann, and de Bruin, 2005). The problem of organizational maturity was first defined by Philip Crosby (Crosby, 1979) - as the organization's ability to professionally employ quality management methods and techniques. The Quality Management Maturity Grid (Crosby, 1979) is regarded as a precursor of the Capability Maturity Model Integration (CMMI) developed by Software Engineering Institute (SEI, 2006; Gibson et al., 2006) and its extension, the Capability Maturity Model Integration (CMMI), which is currently one of the most popular organizational maturity assessment tools (Humprey, 1988; Gibson et al., 2006). The key maturity models originating from this trend are: Business Process Management Maturity Model (Rosemann and de Bruin, 2005; Rosemann et al., 2006), Business Process Orientation Maturity Model (McCormack and Johnson, 2001), Process and Enterprise Maturity Model (Hammer, 2007), Business Process Maturity Model (Object Management Group, 2008), Process Maturity Ladder, Harmon, 2007). An overview of organizational and process maturity models is given by Röglinger et al. (2012). The maturity of organizations is usually measured by a four- or five degree scale and it should address the factors determining the process repeatability, as well as the resources and capabilities that ensure such repeatability. According to Kohlbacher and Reijers (2013), the relevant aspects of maturity evaluation include: process documentation, management commitment, process ownership, process measurement and monitoring, continuous process improvement methods and techniques, as well as organizational culture and structure. A higher level of maturity results in a better control of the results, more accurate forecast of goals, costs and performance, higher effectiveness in reaching the defined goals and greater ability of the organization to plan and implement organizational changes (Lockamy and McCormack, 2004).

\section{Process Management Life Cycle}

The process management life cycle phases are most typically defined based on Deming's Plan-Do-Check-Act or Plan-Do-Study-Act cycle (Kalinowski, 2011), or using the approaches adapted by authors of process management architectures (Jost and Scheer, 2002; BOC, 2007; Nosowski, 2010). The Process Management Life Cycle 
model (BOC, 2007) covers six basic dimensions of process management: Process Strategy, Process Documentation, Process Optimization, Process Implementation, Process Execution and Process Controlling. These dimensions reflect the situation in the analysed area or throughout the organization in terms of the process maturity, while indicating opportunities for improvement and development towards the process management approach. PMLC is a model of procedures for process performance and management. The "Strategy" dimension shows, whether the organization's strategy has been mapped into its processes, especially those strategically significant. The "Documentation" dimension specifies, if the processes of organization have been identified, structured and documented in the form of models. Understanding the organization's processes is a starting point for development of a system for measuring and improving process performance and effectiveness. "Optimization" is the area where process performance and effectiveness is analysed. The "Implementation" area checks, how organization's resources are used in the newly designed processes. "Execution" covers the evaluation of process quality, the security and accessibility of the IT architecture and services, as well as the process risk management. "Controlling" enables managers to evaluate the achievement of process objectives on a regular basis, by means of process monitoring and analysis tools.

\section{Methodology}

The case study covered six basic dimensions distinguished in the Process Management Life Cycle model (BOC, 2007): Process Strategy, Process Documentation, Process Optimization, Process Implementation, Process Execution and Process Controlling. The organization's process maturity evaluation exercise included a questionnaire-based survey of a major company from the fuel sector, listed on the Warsaw Stock Exchange. Employees of the organization representing two different grade levels: Management and Professionals, were asked questions concerning the six process areas of the PMLC model. The responses were expressed in Likert scale from 1 to 5 . When answering the questions, the respondents expressed their subjective perception of the business model maturity, referring to each of the elements. The overall perception - Business Process Maturity Indicator (BPMI) - was computed for the company as an arithmetic mean of the results obtained in the six process areas in the Process Management Life Cycle.

$$
\mathrm{BPMI}=\frac{1}{n} \sum_{i=1}^{n}\left(\frac{1}{k_{i}} \sum_{j}^{k_{i}} x_{i j}\right) \text {, }
$$

Where $x$ - value of the answer in each element $i$ and question $j, j=1 . . k_{i}$ - number of questions in element $i, i-$ number of process area, $n=6$ process areas.

To answer RQ1, the ANOVA Simple Factor analysis was conducted using BPMI, which allowed the evaluation of differences between the groups of respondents. Furthermore, BPMI enabled the examination of correlations between the overall maturity of the organization and the maturity components as per PMLC.

\section{Results}

The business process maturity survey was conducted on a small sample of respondents (47), in the hope that it will be expanded in the future. According to the job scale, the sample included 30 respondents classified as the Grade Level Management (middle and top level management) and 17 Grade Level Professionals. Descriptive statistics of Business Process Maturity Indicator for both groups are summarised in Table 1 and Table 2. 
Table 1

Descriptive statistics of BPMl for Grade Level Management (GL_M)

\begin{tabular}{l|llll}
\hline & Mean & Std. Dev. & Min & Max \\
\hline BPMI & 3.7876 & 0.7157 & 2.3981 & 4.8072 \\
BPMI Strategy & 4.1372 & 0.7376 & 2.6667 & 5.0000 \\
BPMI Documentation & 3.8529 & 0.7464 & 2.7500 & 4.8750 \\
BPMI Optimization & 3.7843 & 0.8457 & 1.8888 & 4.6667 \\
BPMI Implementation & 3.9216 & 0.5426 & 3.2222 & 4.8889 \\
BPMI Execution & 3.5294 & 0.9446 & 2.0000 & 4.8571 \\
BPMI Controlling & 3.5000 & 1.1634 & 1.0000 & 5.0000 \\
\hline
\end{tabular}

Source: Author

Table 2

Descriptive statistics of BPMI for Grade Level Professionals (GL_P)

\begin{tabular}{l|llll}
\hline & Mean & Std. Dev. & Min & Max \\
\hline BPMI & 3.2191 & 0.6323 & 1.7464 & 4.5410 \\
BPMI Strategy & 3.7333 & 0.6970 & 1.7778 & 5.0000 \\
BPMI Documentation & 3.3208 & 0.9189 & 1.7500 & 5.0000 \\
BPMI Optimization & 3.2037 & 0.8656 & 1.2222 & 4.5555 \\
BPMI Implementation & 3.2000 & 0.8157 & 1.8889 & 4.8889 \\
BPMI Execution & 2.9857 & 0.8392 & 1.4286 & 5.0000 \\
BPMI Controlling & 2.8708 & 0.8295 & 1.0000 & 4.5000 \\
\hline
\end{tabular}

Source: Author

In order to answer the RQ1, an ANOVA simple factor analysis was conducted to investigate the significance of differences in the Business Process Maturity Indicators mean values in general and with respect to the six process areas of PMLC in both categories of grade levels: "GL_M" and "GL_P" (Table 3). The total variance (diversity of results) is divided into a part deriving from differences between groups and a part deriving from differences between results within the groups. The results of Business Process Maturity Indicator ANOVA show strongly significant differences in means between the "GL_M" and "GL_P" groups, exceeding the difference within these groups. The outcomes can be used as inputs to RQ1 regarding the organization's process maturity perception by respondents representing different grade levels, showing significantly higher BPMI scoring in the middle and top level management category.

Table 3

Differences in mean significance of BPMI elements between \& within groups Grade Level Management (GL_M) and Grade Level Professionals (GL_P)

\begin{tabular}{l|llll}
\hline ANOVA & MS $_{\mathrm{B}}$ & $\mathrm{MS}_{\mathbf{W}}$ & Test F & p-value \\
\hline BPMI & 3.5071 & 0.4398 & 7.9748 & $0.007^{* *}$ \\
BPMI Strategy & 1.7704 & 0.5065 & 3.4951 & $0.068^{*}$ \\
BPMI Documentation & 3.0723 & 0.7423 & 4.1389 & $0.048^{* *}$ \\
BPMI Optimization & 3.6580 & 0.7372 & 4.9620 & $0.031^{\text {** }}$ \\
BPMI Implementation & 5.6497 & 0.5334 & 10.591 & $0.002^{* *}$ \\
BPMl Execution & 3.2076 & 0.7711 & 4.1599 & $0.047^{* *}$ \\
BPMI Controlling & 4.2954 & 0.9246 & 4.6455 & $0.037^{* *}$ \\
\hline
\end{tabular}

Note: Difference of means is significant at the level: ${ }^{*}(p<0.1) ;{ }^{* *}(p<0.05) ; M S_{B}-$ Mean Square Between groups; MS - Mean Square Within groups

Source: Author 
An in-depth analysis of differences between the "GL_M" and "GL_P" groups" perception of both general and area-specific process maturity was conducted using a correlation matrix (Table 4 and Table 5). All process areas showed a positive correlation, which is compatible with the PMLC model logic. According to GL_M, "Execution", "Optimization" and "Controlling were the aspects with the strongest impact on the general maturity of the organization. These dimensions are strongly correlated throughout the process management cycle. "Optimization" uses data from "Controlling" as inputs for verification of process performance and effectiveness through the prism of objectives. "Execution" informs of the organization's maturity in terms of process control from the organizational and technical point of view and collects data for "controlling". As the process areas referred to above fall within the managers' scope of competence, they were perceived by this group as having a strongest impact on the BPMI level.

Table 4

Correlation coefficients of BPMI for Grade Level Management

\begin{tabular}{l|lllllll}
\hline & BPMI & BPMI_S & BPMI_D & BPMI_O & BPMI_I & BPMI_E & BPMI_C \\
\hline BPMI & 1.0000 & & & & & & \\
BPMI_S & $0.8660^{* * *}$ & 1.0000 & & & & & \\
BPMI_D & $0.6477^{* * *}$ & 0.3890 & 1.0000 & & & & \\
BPMI_O & $0.9314^{* * *}$ & $0.9237^{* * *}$ & $0.4912^{* *}$ & 1.0000 & & & \\
BPMI_I & $0.8671^{* * *}$ & $0.6995^{* *}$ & $0.8507^{* * *}$ & $0.7495^{* * *}$ & 1.0000 & & \\
BPMI_E & $0.9334^{* * *}$ & $0.7564^{* * *}$ & $0.4830^{* *}$ & $0.8125^{* * *}$ & $0.7365^{* * *}$ & 1.0000 & \\
BPMI_C & $0.8873^{* * *}$ & $0.7010^{* *}$ & 0.3565 & $0.8011^{* * *}$ & $0.6023^{* *}$ & $0.9100^{* * *}$ & 1.0000 \\
\hline
\end{tabular}

Note: Significance levels: ${ }^{*} p<0.1,{ }^{* *} p<0.05,{ }^{* * *} p<0.01$

Source: Author

Table 5

Correlation coefficients of BPMI for Grade Level Professionals

\begin{tabular}{l|lllllll}
\hline & BPMI & BPMI_S & BPMI_D & BPMI_O & BPMI_I & BPMI_E & BPMI_C \\
\hline BPMI & 1.0000 & & & & & & \\
BPMI_S & $0.7181^{* * *}$ & 1.0000 & & & & & \\
BPMI_D & $0.8459^{* * *}$ & $0.5277^{* *}$ & 1.0000 & & & & \\
BPMI_O & $0.8110^{* * *}$ & $0.4480^{* *}$ & $0.7133^{* * *}$ & 1.0000 & & & \\
BPMI_I & $0.8369^{* * *}$ & $0.5546^{* *}$ & $0.6571^{* * *}$ & $0.4799^{* *}$ & 1.0000 & & \\
BPMI_E & $0.8128^{* * *}$ & $0.5809^{* * *}$ & $0.6090^{* * *}$ & $0.6446^{* * *}$ & $0.7472^{* * *}$ & 1.0000 & \\
BPMI_C & $0.5415^{* *}$ & 0.2590 & $0.3107^{*}$ & $0.3747^{* *}$ & $0.3934^{* *}$ & 0.1353 & 1.0000 \\
\hline
\end{tabular}

Note: Significance levels: ${ }^{*} p<0.1,{ }^{* *} p<0.05,{ }^{* * *} p<0.01$

Source: Author

According to Professionals, the BPMI level was strongest affected by "Documentation" and "Implementation". Professionals were interested in such areas as business process identification and modelling with the use of modelling notation, as well as practical implementation of these processes in the environment of those who perform them.

\section{Discussion}

The maturity model and the process management life cycle models should be regarded as a formalised set of elements (features) describing fully efficient processes or requirements which, when satisfied, enable the achievement of 
maturity (Rosemann and de Bruin, 2005; Hammer, 2007; Lockamy and McCormack, 2004). It is a form of a roadmap and a standardised method of communication between participants of a project, which has been designed to build a processoriented organization, therefore it is important for both managers and process operators to fully understand their roles and be aware of the organization's maturity when implementing process management (Hammer, 2007; Lockamy and McCormack, 2004). A thorough self-assessment performed using maturity models and life cycle models enables the organization to identify sources of deficiencies, as well as areas for improvement within the continual improvement cycle. Maturity models can be particularly useful for organizations initiating formalised process management, since they facilitate the identification of the current situation, thereby providing motivation to act, while suggesting best practices that could be employed. The Process Management Life Cycle method has been chosen, as the process areas distinguished within the model can be compared in terms of their perception by different grade levels. The findings show that the respondents from the category of Managers perceive their organization more optimistically than the Professionals, which may be explained by the Impression Management theory (Wayne and Liden, 1995), according to which managers may be trying to regulate and control information in their interaction with the personnel and the business environment, so as to give them the best impression of the company, its objectives and management methods (RQ1). The highest scores given to "Process Strategy" confirmed the deep commitment of Managers at the stage of strategy building and the good strategy communication in the organization. The finding is supported by the high perception of maturity by Professinals and by the fact that both grades differed in their perception of maturity least namely this area. The result of ANOVA confirmed that differences were greater between the "GL_M" and "GL_P" groups than inside them (RQ1). Correlation matrix identified differences in the influence of individual process areas on the organization's general process maturity (RQ2). Each of the respondent groups favoured its respective areas of involvement: "Optimization", „Execution”, „Controlling" for "GL_M" and „Documentation", "Implementation" for "GL_P". Managers often participate in the Business Process Management implementation projects in their preparation phases, until the moment of the project launch (documentation, implementation), while showing no commitment later on. Professionals, who are actually involved in process tasks, have a better insight into the operation aspects, which translates into the lower final maturity ranks. Out of all process areas, the "Controlling" and "Execution" dimensions were given lowest scores by both respondent categories, but definitely higher by the Management group, which should not surprise, since namely managers are responsible for the regular evaluation of the process goals achievement by means of process monitoring and analysis tools. The findings support that the process maturity perception depends on the scope of responsibility of personnel evaluating the organization, as well as on the communication of the Business Process Management implementation results (Schmelzer and Sesselmann, 2003).

\section{Conclusion}

The fact that the process approach has been implemented is not a sufficient condition for improving the organization's performance. The process maturity measurement provides a basis for making processes and process areas more efficient, as well as for continual improvement. Maturity models and process management life cycle management models may be used for: 1) describing the current status of the organization, 2) improvement, since the models include 
recommendations for the improvements required and 3) comparative analyses, since they may be referred to as benchmarks for comparison with historical data illustrating process performance and organizational maturity, as well as for comparing maturity perception declared by employees representing different grade levels. It seems that the less diversified is the maturity perception declared by personnel representing various levels in the organization, the more trustworthy is the summarised evaluation of the analysed organization's maturity. One should remember however, that the scope of knowledge about process maturity depends on such factors as: the maturity model design used as a basis of the survey, the objectivism of respondents and researchers alike, the quality of questionnaires used for the survey, the frequency of and the systematic approach to the research activities, or the methods used to communicate the findings throughout the organization (Schmelzer and Sesselmann, 2003). For these reasons, the focus of future research should be on improving the elements listed above and expanding the research sample.

\section{References}

1. BOC (2007), "Process Management Life Cycle (PMLC)", BOC Information System GmbH, available at: http://www.bocpmmc.com/docs/BOC_PMLC folder_web_de.pdf / (accessed September 20 2011).

2. Crosby, P.B. (1979), "Quality is free: The art of making quality certain", McGraw-Hill Book Company, New York.

3. De Bruin, T., Rosemann, M. (2005), "Towards a Business Process Management Maturity Model", in Bartmann, D. Rajola F., Kallinikos J. (Ed.), ECIS 2005 Proceedings of the Thirteenth European Conference on Information Systems, Regensburg.

4. Gibson D.L., Goldenson D.R., Kost K. (2006), "Performance Results of CMMI-Based Process Improvement", Technical Report CMU/SEI-2006-004, pp. 5-6.

5. Hammer, M. (2007), "The process audit", Harvard Business Review, Vol. 85 No. 4, pp. 11 1-123.

6. Harmon, P. (2007), Business process change: A guide for business managers and BPM and Six Sigma professionals, Morgan Kaufmann.

7. Humphrey, W.S. (1988), "Characterizing the software process: a maturity framework", Software, Vol. 5 No. 2, pp. 73-79.

8. Jost, W., Scheer, A.W. (2002), "Business process management: a core task for any company organization", in Scheer, A. W., Kirchmer, M., Jost, W. (Ed.), Business Process Excellence: Aris in Practice, Springer, Berlin Heidelberg, pp. 33-43.

9. Kalinowski, T.B. (2011), "Modele oceny dojrzałości procesów" ["Process maturity assessment models"], Acta Universitatis Lodziensis, Folia Oeconomica Vol. 258, pp.173187.

10. Kohlbacher M., Reijers H. A. (2013), "The effects of process-oriented organizational design on firm performance", Business Process Management Journal, Vol. 19 No. 2, pp. 245-262.

11. Lockamy A., McCormack K.P. (2004), "Development of a chain management process maturity model", Supply Chain Management: An International Journal, Vol. 9 No 4, pp. 272278.

12. McCormack K. P., Johnson W. C. (2001), "Business Process Orientation: Gaining the E-Business Competitive Advantage", $1^{\text {st }}$ edition, CRC Press

13. Nosowski, A. (2010), "Zarzadzanie procesami w instytucjach finansowych" ["Process management in financial institutions"], Wydawnictwo $\mathrm{CH}$ Beck.

14. OMG (2008), "Business Process Maturity Model (BPMM)", version 1.0, OMG Document Number: formal/2008-06-01, Object Management Group, available at: http://www.omg.org / (accessed November 15th 2011).

15. Rosemann M., De Bruin T. (2005), "Towards a Business Process Maturity Model", European Conference on Information Systems (ECIS), Regensburg, Germany. 
16. Rosemann M., De Bruin T., Power B. (2008), "BPM Maturity", in Jeston J., Nelis J. (Ed.), Business Process Management: Practical Guidelines to Successful Implementations, Elsevier, Burlington, pp. 313-329.

17. Röglinger M., Poppelbuss J., Becker J. (2012), "Maturity Models in Business Process Management", Business Process Management Journal, Vol. 18 No. 2, pp. 328-346.

18. Wayne, S. J., Linden, R. C. (1995), "Effects of impression management on performance ratings: A longitudinal study", Academy of Management Journal, Vol. 38 No. 1, pp. 232260.

19. Schmelzer, H.J., Sesselmann, W. (2003), "Geschäftsprozessmanagement in der Praxis" ["Business Process Management in Practice"], Carl Hanser Verlag, München.

20. SEI (2006), Appraisal Requirements for CMMI, Version 1.2 (ARC, V1.2), Technical Report CMU/SEI-2006-TR-011 ESC-TR-2006-011, Software Engineering Institute, Carnegie Mellon University.

21. Zwicker, J., Fettke, P., Loos P. (2010), "Business Process Maturity in Public Administrations", in vom Brocke J., Rosemann M. (Ed.), Handbook on Business Process Management 2, Springer, Berlin Heidelberg, pp. 369-396.

\section{About the author}

Renata Gabryelczyk, PhD, Assistant Professor at the Department of Information Systems and Economic Analysis, Faculty of Economic Sciences and partner of Digital Economy Lab at the University of Warsaw. Her academic experience also includes studying at Institute for Information Systems at Saarland University, as well as research fellowships at scientific centres in Heidelberg, Constance and Vienna. Professional pursuits: modeling and analyzing business processes, ICT, facility management, strategic accounting. Additionally, she is a member of the Polish Certificate of BPMN in Systems Research Institute of the Polish Academy of Science. Author can be contacted at r.gabryelczyk@delab.uw.edu.pl 